\title{
The Future of Medical Publishing
}

\section{O Futuro da Publicação Médica}

Trish GROVES $\rrbracket^{1}$

Acta Med Port 2018 Sep;31(9):447-448 - https://doi.org/10.20344/amp.11011

Keywords: Access to Information; Periodicals as Topic/trends; Publishing/trends

Palavras-chave: Acesso à Informação; Publicação/tendências; Revistas/tendências

In many ways the future is already here, and it may herald the death of medical journals. Research funders, universities, and authors are publishing their own research online, bypassing the usual publishers. The 'paper' is being superseded by a whole range of interlinked online outputs. Universities, research funders, and governments are shifting away from Journal Impact Factor as an indicator of academic performance. And patients are beginning to drive research, clinical education, and health policy.

The Internet and World Wide Web have already revolutionised publishing, accelerating many journals' processes and facilitating the free dissemination of articles (often with web appendices) and, often, whole journals. Going further, $30 \%-40 \%$ of medical journal articles are now available with Open Access. ${ }^{1}$ Its purest 'Gold' form is much more than simply free access. Crucially, with this kind of full Open Access publishing, licences ensure that authors keep copyright for their work and readers can use and share that work widely without asking or paying. ${ }^{2}$ Open Access was driven initially by activists, but it has thrived because of research funders' desire for maximum reach, along with academic libraries' concerns about journal subscription costs.

Despite these innovations, most medical journals cling to tradition. They publish papers in the centuries-old IMRaD format (Introduction, Methods, Results, and Discussion). They exert tight control on research dissemination, barring authors from submitting work simultaneously to several journals and from publicising it before journal release. And, although some online journals have opened up their peer review processes, many still anonymise reviewers' reports.

But, quite suddenly, we are seeing a fundamental shift that could bypass many journals and publishers completely and kick others firmly into the $21^{\text {st }}$ century. This has been driven by three main things: pressure to share research ever more rapidly, worries about rising Open Access fees, and disruptive innovation. At its heart is rapid online posting of preprints, which are preliminary versions of articles checked for clarity but not yet peer reviewed. They are often accompanied by additional files that make the research more transparent and reproducible such as protocols, anonymised datasets, data directories, and the statistical code used to run analyses. These Open Science practices has been used for years in other fields but are relatively new in medicine. Worries that such unreviewed content might be misused for clinical care are as yet unfounded, not least because they are clearly labelled as 'not yet peer reviewed'.

What's really new, and most radical, is the rise of Open Research Platforms. These comprise systems for submission, preprint posting, peer review, and publishing but they are not journals. Although their web services and processes are provided by a technology company or publisher (with Open Research Central, from the company that owns F1000Research, leading the way ${ }^{3}$ ), each platform is leased, branded, and led by a research funder or an academic institution. Authors whose research has been funded by these organisations can submit and disseminate their work quickly, without editorial filtering and without charge. The European Commission will soon launch such a platform for Horizon 2020 grant holders, ${ }^{4}$ and other research funders including The Wellcome Trust, The Bill \& Melinda Gates Foundation, and the African Academy of Sciences have already done so. Some universities are following suit. The compelling message to researchers, from the organisation that funded or supported their work, is 'avoid rejections and delays at journals: come straight to us and we'll get your research online immediately, avoiding editorial bias'.

Given all this, and the fact that academic evaluation systems are abandoning Journal Impact Factor as a performance indicator, ${ }^{5}$ who needs journals? Journals at the top of the tree can probably still rely on their prestige, quality, and big budgets for the foreseeable future. Moreover, they will innovate - for example by adding data sharing and more patient-centred research - while continuing to publish the most influential research, education, and debate. They can have real impact and their authors and readers will keep coming back.

Journals with fewer resources may find it tough to survive. The best will have to work even harder to sustain their budgets, to remain relevant, and to meet people's needs. Many smaller journals (and, in time, probably those that depend solely on Open Access author fees) will have to stop publishing research if authors shift largely to the free, rapid Open Research Platforms. To maintain relevance, such journals might opt to work with producers of rapid evidence reviews.

\footnotetext{
1. Editorial Consultant. Oxfordshire. United Kingdom.

$\bowtie$ Autor correspondente: Trish Groves. trish.groves@bmj.com

Recebido: 03 de julho de 2018 - Aceite: 03 de julho de 2018 | Copyright @ Ordem dos Médicos 2018
} 
These use machine learning techniques to sift and synthesise evidence and curate it into user-friendly clinical practice guidelines. ${ }^{6}$ It's hard to predict where technology for personal communication is heading but, in the near future, journal pages that are optimised for smartphones and for social media are more likely to be read than those that demand readers' time and concentration on a laptop. And, as clinical practice moves ever closer to shared decision making, journals for clinicians might ask authors to work with patients to co-produce education articles, and might invite patients to be reviewers and editorial board members. ${ }^{7}$

All such innovations cost time and money, however, and journal owners will need to be supportive and open to change. Medical associations and societies may have to levy higher membership fees to invest properly in their journals. Dr Stephen Lock, editor of The BMJ between 1974-

\section{REFERENCES}

1. European Commission. Open access to publications: Percentage of open access publications (gold and green) by FOS (fields of science and technology). [accessed 2018 Jul 2]. Available from: https://ec.europa.eu/ info/research-and-innovation/strategy/goals-research-and-innovationpolicy/open-science/open-science-monitor/trends-open-accesspublications_en.

2. Scholarly Publishing and Academic Resources Consortium (SPARC), PLOS, and Open Access Scholarly Publishers Association (OASPA). HowOpenlslt? A Guide for Evaluating the Openness of Journals. [accessed 2018 Jul 2]. Available from: https://sparcopen.org/our-work/ howopenisit/.
90 , used to say that journals were like laundries, taking in washing and pegging the clean items on the line for all to see (an inadvertently prescient notion, two decades before the notion of 'online'). In these busy times, journals that are efficient, useful, helpful, and have good reputations - like the best laundries - will probably have the greatest chance of staying open.

\section{COMPETING INTERESTS}

Trish Groves worked at The BMJ from 1989-2018 (latterly as deputy editor) and was editor-in-chief of BMJ Open from 2011-2018. Both The BMJ and BMJ Open receive income from Open Access publishing fees. Trish Groves is now an associate editor at The BMJ but is also an editorial consultant whose work may include advocacy for Open Access and Open Science.

3. Open Research Central. [accessed 2018 Jul 2]. Available from: https:// openresearchcentral.org.

4. European Commission 2017. Towards a Horizon 2020 platform for open access. [accessed 2 July 2018]. Available from: https://ec.europa. eu/research/openscience/pdf/information_note_platform_public. pdf\#view=fit\&pagemode=none.

5. The Declaration on Research Assessment (DORA). [accessed $2018 \mathrm{Jul}$ 2]. Available from: https://sfdora.org.

6. MAGIC: Making Grade the irresistible choice. [accessed 2018 Jul 2] Available from: http://magicproject.org.

7. Godlee F. Our commitment is to patient partnership. BMJ. 2017;356:j939. 